\title{
The use of pedicled abdominal flap to salvage a necrotic forearm - a case study
}

\begin{abstract}
Background: Pedicled abdominal and groin flaps have since the 70 s and 80 s continued to provide reliable solutions for upper limb injuries that require flap cover. In recent times reconstructive surgeons have found the use of free flaps a better alternative. However, in centres where microsurgery facilities are not available or where the patient cannot afford such services, the pedicle flaps continue to have an important role. Interestingly, some literature states that the long term outcomes of successful pedicled flaps are equal or even better than free flaps. Abdominal flaps together with the groin flaps continue to be the workhorse flaps in the developing world as well as at our centre for major hand injuries with tissue loss.
\end{abstract}

Aim: The aim of this work is to point out the reliability of the abdominal flap leading to a good clinical outcome.

Case presentation: This is a case report of an 8-year-old boy, who sustained a closed fracture to the left forearm. He was taken to a traditional bone setter who wrapped the arm up with herbs. However, after about 2 weeks it was noticed the arm had deteriorated significantly. He presented to our centre 3 weeks after the injury., On arrival at the 37 Military Hospital, it was noticed that the bones of the forearm were exposed, with extensive ulceration and necrotizing of tissue of the lateral extensor and whole flexor surfaces of the left forearm. The wound was generally septic. The wound was debrided and an Abdominal flap cover was done to salvage his upper limb.

Conclusion: The abdominal flap provides a reliable option for reconstruction and salvage of the upper limb with good colour and texture match. Together with the Groin Flaps, Abdominal Flaps continue to be dependable additions in the quiver of the reconstructive surgeon in the developing world.

Keywords: abdominal flaps, groin flaps, fascio cutaneous flaps, traditional bone setters
Volume 5 Issue 6 - 2020

Kwesi O. Nsaful,' C Tetteyfio- Koney, ${ }^{2}$ EO Apraku-Brako,' 'T Mahama-Toure, 'AA Avoka, ' A Antwi- Afriyie, ${ }^{2}$ HN Atampugre' 'Plastic, Reconstructive Surgery and Burns Unit, 37 Military Hospital,Accra, Ghana

${ }^{2}$ Department of Anaesthesia, 37 Military Hospital,Accra, Ghana

Correspondence: Kwesi Okumanin Nsaful, Plastic, Reconstructive Surgery and Burns Unit, 37 Military Hospital, Accra, Ghana, Tel +233243706270, Email knaful@yahoo.co.uk

Received: October 25, 2020 | Published: November 18, 2020

\section{Introduction}

The use of the Pedicled Abdominal and Groin Flaps have been very popular since the 70 s and 80 s for cover of hand injury defects. ${ }^{1,2}$ However, in recent times reconstructive surgeons have found the use of free flaps a better alternative. One disadvantage of the Pedicled Abdominal Flap is the fact that it requires staged procedures and will require increased hospital stay. ${ }^{1,3,4}$ Additionally discomfort and stiffness of the limb are often among patient complaints.

However in centres where microsurgery facilities are not available or where the patient cannot afford such services the pedicle flaps continue to have an important role. in spite of all the attractiveness and plaudits associated with free flap surgery there is indeed some interesting Literature that states that the long term outcomes of successful Pedicled Flaps are equal or even better than free flaps. ${ }^{4}$ As a result, Abdominal Flaps together with the Groin Flaps continue to be the workhorse flaps in the developing world as well as at our centre for major hand injuries with tissue loss.

We present a case report of upper limb injury requiring an abdominal flap coverage, with an aim to point out the reliability of the abdominal flap leading to a good clinical outcome.

\section{Anatomy}

The blood supply of the lower abdominal skin is well-described ${ }^{5}$. The arteries of importance with regards to the Anterior Abdominal Flaps are

The Superficial External Pudendal Artery (SEPA)

The Superficial Inferior Epigastric Artery (SIEA)

The Paraumbilical Perforators (PUP)

The SEPA arises from the femoral artery about $1 \mathrm{~cm}$ below the inguinal ligament. The artery passes medially toward the pubic tubercle and then ascends toward the umbilicus. Hence the SEPA Flap is designed along a line drawn from the umbilicus to the pubic tubercle.

The SIEA arises from the femoral artery just below the midpoint of the inguinal ligament. The artery ascends toward the umbilicus lateral to the SEPA; hence SIEA Flaps are designed lateral to SEPA Flaps.

The Paraumbilical Perforators (PUP) arise from the deep inferior epigastric artery to supply the paraumbilical skin. The perforators radiate around the umbilicus like the spokes of a wheel. 
The Flap raised in this presentation was based on the Paraumbilical Perforators.

The Groin Flap is based on the superficial circumflex iliac artery (SCIA). It arises from the femoral artery $2 \mathrm{~cm}$ below the inguinal ligament, crosses the sartorius muscle, and runs laterally toward the anterior superior iliac spine. Hence Groin Flaps are designed along the course of the SCIA. The territories of these arteries are quite well described (Figure 1).
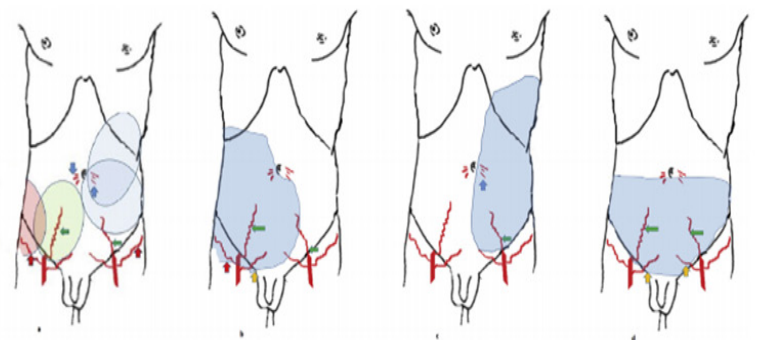

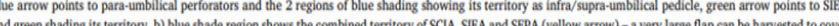
ind green shading its territory. b) blue shade region shows the combined teritiory of SCIA, SIEA and SEPA ( yellow arrow) - a very large flap can be havested to cone both sides of forearm and hand. c) shows the combined teritory of SIEA and para-umbilical perforators - this can cover large defects of foream and elbow. $O$

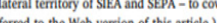

Figure I Blood Supply to the skin of the Lower Abdomen (Acharyaa A.M, Ravikiranb N, Jayakrishnana K.N, Bhata A.K, The role of pedicled abdominal flaps in hand and forearm composite tissue injuries: Results of technical refinements for safe harvest. Journal of Orthopaedics I6(2019) 369-376).

\section{Case report}

\section{Case summary}

This is a case report of an 8yr-old boy, who lives with both parents in a family house in a suburb of Accra. He is the first of 3 male children. His Father is a housekeeping staff at a hotel while his mother is unemployed. Three weeks prior to presentation, whilst on a visit to his grandfather in the Eastern Region, about 1 hour 45 minutes' drive from Accra, he sustained a closed fracture to the left forearm whilst playing with friends. He was taken to a herbalist who wrapped the arm up with herbs. However, after about 2 weeks, a visiting uncle noticed the arm had deteriorated significantly, hence, the parents were prompted to bring him back to Accra. He was taken to a peripheral facility where he was seen and referred to 37 Military hospital immediately for management.

On arrival at the Trauma and Surgical Emergency Unit of the 37 Military Hospital, he was afebrile, not pale, but generally unwell and was reported to have vomited once prior to presentation. His vital signs were as follows: $\mathrm{T}=36.8 \mathrm{C} \mathrm{P}=127, \mathrm{RR}=34, \mathrm{SPO} 2=99 \%$. The bones of the forearm were exposed, with extensive ulceration and necrotizing of tissue of the lateral extensor and whole flexor surfaces of the left forearm (Figure 2) (Figure 3). The radial and brachial arteries were palpable and capillary refill was less than 3 secs. Investigations revealed a haemoglobin level of $12.7 \mathrm{~g} / \mathrm{dl}$, WBC of $8.39 \times 10>3$ with $75.6 \%$ neutrophils. The renal function was fairly normal. There was a complete fracture of the mid-shaft of the left ulna and radius on the x-ray. The wound dressing was done and he was started on IV Cefuroxime 500mg bd x $72 \mathrm{hrs}$, IV Metronidazole 250mg tds x $72 \mathrm{hrs,}$ IV Paracetamol 500mg tds X $72 \mathrm{hrs}$.

On the day after presentation, he was taken to the operating theatre by the orthopaedics team. There, under general anaesthesia wound debridement was done, Findings were: Necrotic flexor muscles and tendons exposed left radius and ulna. The wound was generally septic.

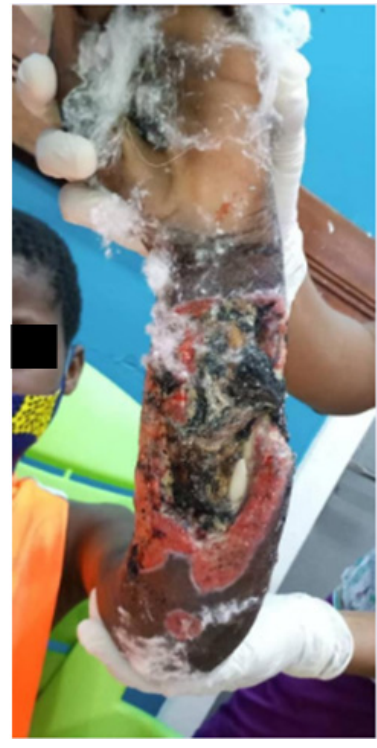

Figure 2 Necrotic flexor aspect of forearm.

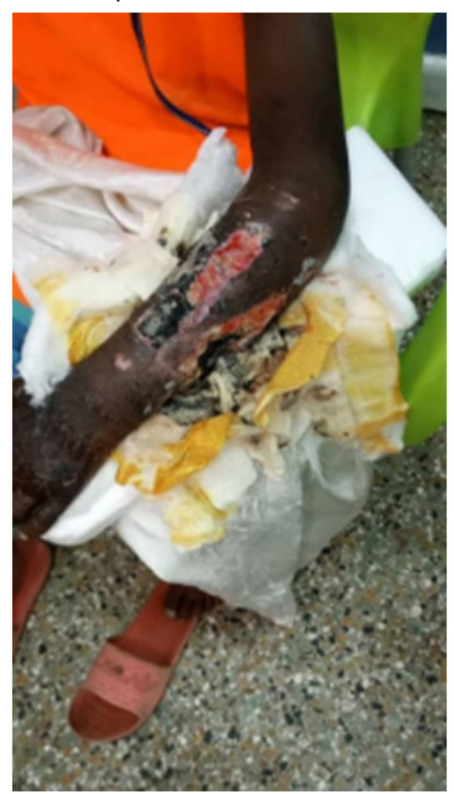

Figure 3 Extensor view of forearm with bone exposed.

On postoperative day 1, plastic consult was sort. He was seen by the plastic surgery unit. After various options had been considered, the conclusion was that the best option was an anterior abdominal Flap.

Abdominal Flap cover was done 14 days after the wound debridement. There was the need to allow time for revascularization and some granulation tissue formation. The surgery was done under general anaesthesia. Intraoperative findings were an ulcer about $5 \mathrm{x}$ $15 \mathrm{~cm}$ on the flexor surface of the forearm with ulna exposed. The ulcer extended to the Dorso-ulnar and Radial aspects of the forearm with a thin intervening portion (about $3 \mathrm{~cm}$ wide) of the surface intact. Granulation tissue on the denuded surfaces was however healthy. An axial fascio-cutaneous flap was raised from the left lumbar region of the abdomen based on Paraumbilical Perforators on the side to cover the defect. (Figure 4) (Figure 5). A split skin graft was taken from the left thigh to cover the flap site on the abdomen. (Figure 6). The arm was dressed and plastered to the abdomen. The Flap was left intact till 
day 21 when the flap was divided. Inspection of the flap 5 days post division showed the flap was viable (Figure 7).

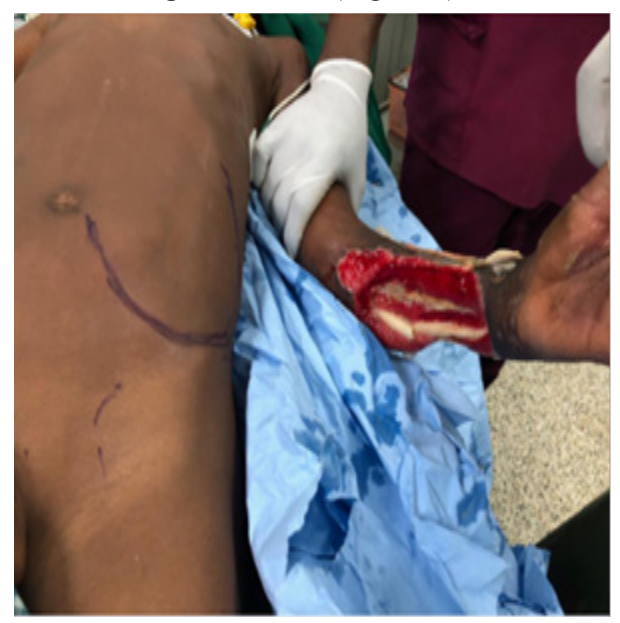

Figure 4 Flap markings made.

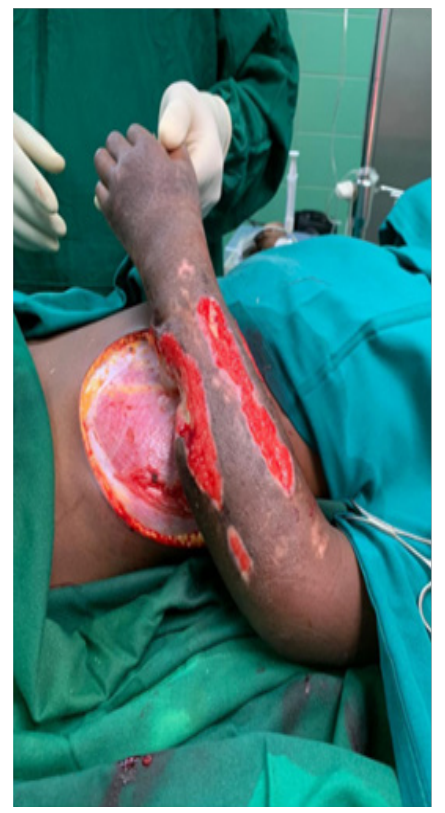

Figure 5 Flap secured in place at the recipient site.

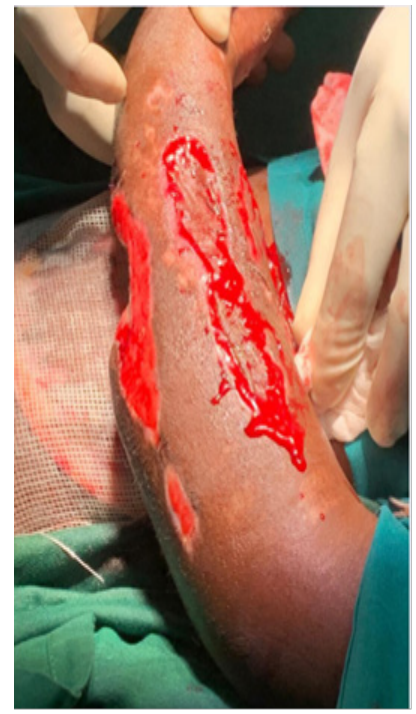

Figure 6 Flap donor site covered with SSG.

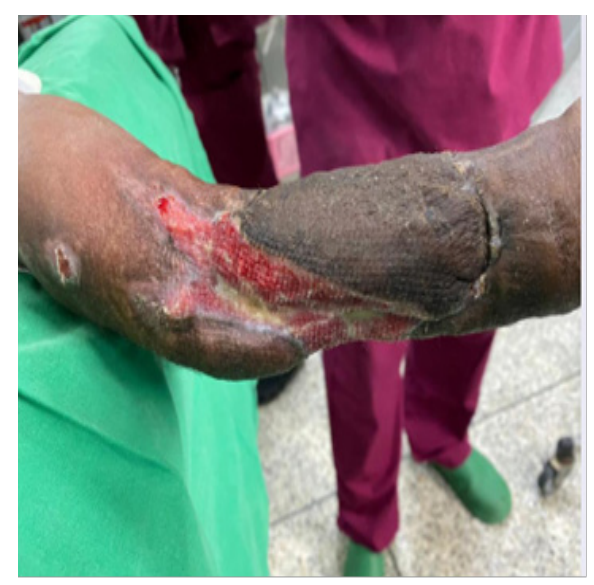

Figure 7 Flap Day 5 post division.

Flap inset was done 14 days after the flap division (Figure 8) Primary closure was achieved for the remaining abdominal defect at the Flap donor site.

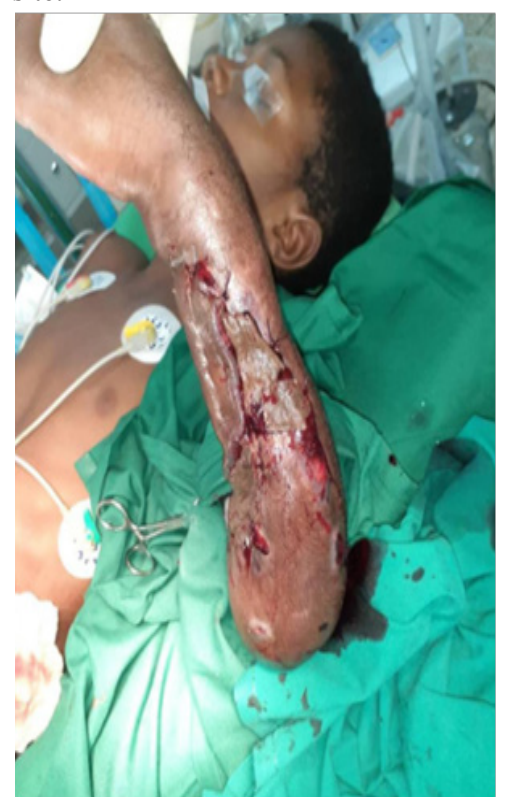

Figure 8 Flap inset done, forearm defect covered.

An x-ray of the left forearm suggested good callus formation at fracture sites of radius and ulna, however, the fusion at the fracture sites were angulated. These are expected to mold with time.

The postoperative period was uneventful. The wounds healed well. On day 5 post flap inset, physiotherapy sessions were started.

$\mathrm{He}$ is able to pronate and supinate the forearm. He is also able to extend and flex at the wrist joint.

\section{Discussion}

Traditional medicine is a health practice of traditional knowledge and skill of medical aspects that passed over a generation before the era of modern medicine. ${ }^{6,7}$ The Traditional Bone Setters (TBS) are lay practitioners who practice management of dislocations and fractures without having had any formal training. Despite the access and availability of modern health care, people still patronize their services. Work done by Kuubiere et al showed that in Ghana up to $25 \%$ of people prefer to see TBS when they sustain a fracture than to present to a hospital. ${ }^{8}$ 
The reason for the preference of TBS includes easy accessibility, cultural belief, quick service, cheaper fee, pressure from friends and families, and utilization of incantation and concoctions. ${ }^{8-15}$ Another important reason for the preference of TBS is the fear of amputation. ${ }^{15}$

Unfortunately many suffer bad outcomes with TBS and present at a health facility in dire circumstances. In such situations, the dreaded limb amputation may be the inevitable solution. However in this case with the use of the abdominal flap the limb was salvaged.

The abdominal flap together with the groin flap continues to be reliable workhorse flaps in the field of reconstructive surgery. They may be employed in several situations.

Some documented situations in which these flaps have been indicated include

i. Complex hand defects in children aged less than 2 years ${ }^{16}$

ii. High-voltage electric burns with the hand surviving on collateral circulation $^{17,18}$

iii. Length preservation of multiple digital amputations. ${ }^{19}$

In all, these very good outcomes were achieved.

In order to increase the reliability of the abdominal flap, flap delay has to be may be done. Flap delay is often necessary for circumferential wounds around the digits where the area of inset is less or near circumferential and in large wounds of the forearm. The delay procedure has been extensively investigated and tested clinically as well. ${ }^{20}$ Though some works have shown no necrosis others have shown various level of necrosis as high as 33\% with ischaemic preconditioning. ${ }^{20,21}$ A major drawback of a flap delay has been the need for an additional surgical procedure and a further increase in the duration of immobilization in an unsafe position. This means hand therapy program often gets held up leading to stiffness.

Abdominal flap may be used as soft tissue cover alone or with the repair of the underlying critical structures such as tendon repair, neurovascular repair as well as reduction and fixation of fractures. In large defects, only the critical area of exposed bone, joint, tendon, or neurovascular tissue is covered whereas the rest of the areas are covered with split skin grafts.

When large areas are required for cover, territories of the SCIA, SIEA, and SEPA can be incorporated. ${ }^{22,23}$

A common complication which may be experienced with the abdominal flap is marginal flap necrosis, which represents necrosis at the distal edge leading to poor and delayed wound healing. Most of these will heal after regular dressing or secondary suturing after debridement. $^{23}$

Flap infection which may occur can be managed by debridement and antibiotics.

One of the drawbacks of pedicled flap cover is its lack of sensation. This is very disabling if the fingers and the thumb are involved. With our patient, the injury he presented with had already damaged the ulnar and median nerves.

\section{Conclusion}

The abdominal flap provides a reliable option for reconstruction and salvage of the upper limb with good colour and texture match. Together with the groin flaps, abdominal flaps continue to be dependable additions in the quiver of the reconstructive surgeon in the developing world. Abdominal flaps often give satisfactory results.

\section{Patient consent}

The parents of the patient provided written consent for the use of his image.

\section{Acknowledgments}

None.

\section{Conflicts of interest}

No potential conflict of interest relevant to this article was reported.

\section{References}

1. Al-Qattan MM, Al-Qattan AM. Defining the indications of pedicled groin and abdominal flaps in hand reconstruction in the current microsurgery era. J Hand Surg Am. 2016;41(9):917-927.

2. McGregor IA, Jackson IT. The groin flap. Br J Plast Surg.1972;25(1):3e16.

3. Goertz O, Kapalschinski N, Daigeler A, et al. The effectiveness of pedicled groin flaps in the treatment of hand defects: results of 49 patients. $J$ Hand Surg Am. 2012;37(10):2088-2094.

4. Sabapathy SR, Bajantri B. Indications, selection, and use of distan pedicled flap for upper limb reconstruction. Hand Clin. 2014;30(2):185199

5. Boyd JB, Taylor GI, Corlett R. The vascular territories of the superior epigastric and the deep inferior epigastric systems. Plast Reconstr Surg. 1984;73(1):1e16.

6. WHO. World health organization congress on traditional medicine. Beijing, China. 2008.

7. Dada AA, Yinusa W, Giwa SO. Review of the practice of TBSin Nigeria. Afr Health Sci. 2011;11(2):262-265.

8. Kuubiere CB, Abass A, Majeed SF. Patients preference for traditional bonesetters in Northern Ghana AlAmeen. J Med Sci. 2015;8(2):115-118.

9. Omololu AB, Ogunlade SO, Gopaldasani VK. The practice of traditional bonesetting: training algorithm. Clin Orthop Relat Res. 2008;466(10):2392-8.0371-8.

10. Orjioke CJ. Does traditional medicine have a place in Primary Health Care. Orient J Med. 1995;7(1 and 2):1-3.

11. Thanni LOA. Factors influencing patronage of traditional bonesetters West Afr J Med. 2000;19(3):220-224.

12. Onuminya JE. The role of the traditional bone setter in Primary fracture care in Nigeria. S Afr Med J. 2004;94(8):652-658.

13. Omololu B, Ogunlade SO, Alonge TO. The complications seen from the treatment by traditional bone setters. West Afr J Med. 2002;21(4):335337.

14. Solagberu BA. Long bone fractures treated by traditional bonesetters: a study of patients' behaviour. Trop Doct. 2005;35(2):106.

15. Marcel JH, Arie"S, Harry HJ, et al. Fracture treatment by bonesetters in central Ghana: patients explain their choices and experiences. Tropical Medicine and International Health. 2007;12(4):564-574.

16. Zucker RM, Cleland HJ, Haswell T. Syndactyly correction of the hand in Apert syndrome. Clin Plast Surg. 1991;18(2):357-364.

17. Khandelwal S. An abdominal flap to the same right forearm and the hand following a high-voltage electric burn in a case report. J Clin Diagn Res. $2013 ; 7(7): 1473-1475$ 
18. Tiwari VK, Sarabahi S, Chauhan S. Preputial flap as an adjunct to groin flap for the coverage of electrical burns in the hand. Burns. 2014;40(1):e4 e7.

19. Mathew P, Venkatramani H, Sabapathy SR. Mini-abdominal flaps fo preservation of digital length in an 18-month old child. J Hand Surg Eur Vol. 2013;38(1):89-91.

20. Harder Y, Amon M, Laschke MW, et al. An old dream revitalised: preconditioning strategies to protect surgical flaps from critical ischaemia and ischaemia-reperfusion injury. J Plast Reconstr Aesthet Surg. 2008;61(5):503-511.
21. Goertz O, Kapalschinski N, Daigeler A, et al. The effectiveness of pedicled groin flaps in the treatment of hand defects: results of 49 patients. $J$ Hand Surg Am. 2012;37(10):2088-2094.

22. Koshima I, Mardini S, Wei FW. Groin flap and superficial circumflex iliac artery perforator flap, in: F Wei, S Mardina. editors. Flaps and reconstructive surgery, Elsevier, London. 358-374.

23. Acharyaa AM, Ravikiranb N, Jayakrishnana $\mathrm{KN}$, et al, The role of pedicled abdominal flaps in hand and forearm composite tissue injuries: Results of technical refinements for safe harvest. Journal of Orthopaedics. 2019;16:369-376. 